\title{
Transient Receptor Potential Melastatin 7 as an Independent Prognostic Factor in Human Esophageal Squamous Cell Carcinoma
}

\author{
SHINGO NAKASHIMA ${ }^{1 *}$, ATSUSHI SHIOZAKI ${ }^{*}$, DAISUKE ICHIKAWA ${ }^{1}$, SHOICHIRO HIKAMI $^{1}$, \\ TOSHIYUKI KOSUGA ${ }^{1}$, HIROTAKA KONISHI ${ }^{1}$, SHUHEI KOMATSU ${ }^{1}$, HITOSHI FUJIWARA ${ }^{1}$, \\ KAZUMA OKAMOTO $^{1}$, MITSUO KISHIMOTO ${ }^{2}$, EIICHI KONISHI ${ }^{2}$ and EIGO OTSUJI ${ }^{1}$ \\ ${ }^{1}$ Division of Digestive Surgery, Department of Surgery, and ${ }^{2}$ Department of Pathology, \\ Kyoto Prefectural University of Medicine, Kyoto, Japan
}

\begin{abstract}
Background: Transient receptor potential melastatin 7 (TRPM7) is a $\mathrm{Mg}^{2+} / \mathrm{Ca}^{2+}$-permeable channel with kinase activity and is expressed in many solid tumor types. However, it has not been evaluated in esophageal squamous cell carcinoma (ESCC). The aim of this study was to evaluate the prognostic impact of TRPM7 in ESCC and to determine the role of TRPM7 in proliferation, migration and invasion of ESCC. Materials and Methods: Immunohistochemistry of TRPM7 for 52 primary tumor samples obtained from patients with ESCC undergoing esophagectomy was performed. Expression of TRPM7 in human ESCC cell lines was analyzed by real-time polymerase chain reaction $(P C R)$. Knockdown experiments were conducted with TRPM7 siRNA, and the effect on cell proliferation, migration and invasion was analyzed. Results: Immunohistochemical staining showed that TRPM7 was found in the cytoplasm of carcinoma cells, and that expression was an independent prognostic factor of good postoperative survival. Suppression of TRPM7 expression with TRPM7-siRNA increased the proliferation, migration and invasion of TE5 ESCC cells. Conclusion: The expression of TRPM7 has an impact on the prognosis of patients with ESCC.
\end{abstract}

The transient receptor potential (TRP) family of trans-plasma membrane channels act as cellular sensors of physical and

This article is freely accessible online.

*These Authors contributed equally to this study.

Correspondence to: Dr. Atsushi Shiozaki, Division of Digestive Surgery, Department of Surgery, Kyoto Prefectural University of Medicine, 465 Kajii-cho, Kamigyo-ku, Kyoto 602-8566, Japan. Tel: +81 752515527, Fax: +81 752515522, e-mail: shiozaki@koto.kpu-m.ac.jp

Key Words: TRPM7, melastatin 7, esophageal cancer, prognostic factor. chemical stimuli by modulating ionic homeostasis (1). Transient receptor potential malastatin 7 (TRPM7) is composed of a permeable $\mathrm{Ca}^{2+}-\mathrm{Mg}^{2+}$ ion channel and an inherent serine/threonine kinase (2) and regulates many cellular processes including survival $(3,4)$, proliferation (5-10), migration (8-14) and invasion (8). TRPM7 plays an important role in the proliferation of head and neck tumor cells (7), glioma cells (8), prostate cancer cells (9) and bladder cancer cells (10). Furthermore, TRPM7 regulates the migration of human nasopharyngeal carcinoma cells (12), breast cancer cells (13) and human pancreatic ductal adenocarcinoma cells (14). To our knowledge, the value of TRPM7 expression in esophageal squamous cell carcinoma (ESCC) has not been evaluated. The objectives of the present study were, therefore, to analyze expression of TRPM7 in human ESCC samples and determine its relationships with clinicopathological features and prognosis. Furthermore, we investigated roles of TRPM7 in cell proliferation, migration and invasion of ESCC cells.

\section{Materials and Methods}

Patients and primary tissue samples. ESCC tumor samples were obtained from 52 patients with histologically proven primary ESCC who underwent esophagectomy (potentially curative R0 resection) at the Kyoto Prefectural University of Medicine (Kyoto, Japan) between 1999 and 2007. The samples were embedded in paraffin after $24 \mathrm{~h}$ of formalin fixation. Only those patients who did not develop synchronous tumors or multiple metachronous tumors and who did not receive preoperative chemotherapy or radiation therapy met the eligibility criteria. All patients gave their written informed consent for use of their samples and data. Relevant clinicopathological and survival data were obtained from the hospital database. Staging was principally based on the International Union Against Cancer/TNM Classification of Malignant Tumors (seventh edition) (15).

Immunohistochemistry. Paraffin sections (4- $\mu \mathrm{m}$ thick) of tumor tissue were subjected to immunohistochemical staining for TRPM7 using the avidin-biotin-peroxidase method. Briefly, paraffin sections 
were dewaxed in xylene and hydrated through a graded series of alcohols. Antigen retrieval was performed by heating the samples in Dako REAL Target Retrieval Solution (Dako, Glostrup, Denmark) for $40 \mathrm{~min}$ at $95^{\circ} \mathrm{C}$. Endogenous peroxidase activity was quenched by incubating the sections for $30 \mathrm{~min}$ in $0.3 \% \mathrm{H}_{2} \mathrm{O}_{2}$. The sections were treated with protein blocker for $1 \mathrm{~h}$ at room temperature, and then they were incubated overnight at $4^{\circ} \mathrm{C}$ with antibody to TRPM7 (rabbit polyclonal TRPM7 antibody, diluted 1:10,000; Abcam, Cambridge, UK). The avidin-biotin-peroxidase complex system (Vectastain ABC Elite kit; Vector Laboratories, Burlingame, CA, USA) was used for color development with diaminobenzidine tetrahydrochloride. The sections were counterstained with hematoxylin. Finally, the sections were dehydrated through a graded series of alcohols, cleared in xylene, and mounted. Control sections of known positively staining ESCC were included in each antibody run, and negative control sections were produced by omitting the primary antibody.

Immunohistochemical samples stained with TRPM7 were graded semi-quantitatively by considering both the staining intensity and percentage of positively stained tumor cells in all tumor fields in one slide including the center of the tumor using an intensity proportion score (IP score) (16). Staining intensity was scored as 0 (no staining), 1 (weak staining), 2 (moderate staining), or 3 (strong staining). The score of each sample was calculated as the total of the product of intensity and proportion scores (0 to 3.0).

Cell lines. The poorly differentiated human ESCC cell lines TE2,TE5, TE9, and TE13 were obtained from the Cell Resource Center for Biomedical Research Institute of Development, Aging, and Cancer (Tohoku University, Sendai, Japan) (17). The human ESCC cell lines KYSE70 and KYSE170 were obtained from Kyoto University (Kyoto, Japan) (18). These cells were grown in RPMI1640 medium (NacalaiTesque, Kyoto, Japan) supplemented with $100 \mathrm{U} / \mathrm{ml}$ of penicillin, $100 \mu \mathrm{g} / \mathrm{ml}$ of streptomycin, and $10 \%$ fetal bovine serum. The cells were cultured in flasks and dishes in a humidified incubator at $37^{\circ} \mathrm{C}$ under $5.0 \% \mathrm{CO}_{2}$ in air.

Real-time quantitative reverse transcriptase-polymerase chain reaction (RT-PCR). Total RNA was extracted using an RNeasy Mini Kit (Qiagen, Valencia, MD, USA). Levels of messenger RNA (mRNA) expression were measured by quantitative real-time fluorescence detection (ABI StepOnePlus ${ }^{\mathrm{TM}}$ Sequence Detection System; Applied Biosystems, Foster City, CA, USA) using TaqMan Gene Expression Assays (Applied Biosystems). The expression level of TRPM7 gene (Hs00918956_m1; Applied Biosystems) was measured, and normalized against the housekeeping gene beta-actin (ACTB, Hs01060665_g1; Applied Biosystems).

Small interference RNA (siRNA) transfection. For knocking-down TRPM7 expression, siRNA targeting TRPM7 (Stealth RNAi ${ }^{\mathrm{TM}}$, siRNA-TRPM7-1; \#HSS123307; Invitrogen, Carlsbad, CA, USA) and control siRNA were transfected into ESCC cells $(10 \mathrm{nmol} / \mathrm{l})$ using Lipofectamine RNAiMAX (Invitrogen) according to the manufacturer's instructions. The knockdown of the target gene was confirmed by quantitative real-time RT-PCR.

Cell proliferation assay. Cells were seeded onto 6-well plastic plates at a density of $1.0 \times 10^{5}$ cells per well and incubated at $37^{\circ} \mathrm{C}$ with $5 \%$ $\mathrm{CO}_{2}$. At $24 \mathrm{~h}$ after the cell seeding, siRNA transfection was performed. At $48 \mathrm{~h}$ after siRNA transfection, the cells were detached from the plates using trypsin-EDTA and were counted using Countess ${ }^{\circledR}$ Automated Cell Counter (Invitrogen). Each sample was independently counted three times, and each assay was performed in triplicate.

Analysis of cell migration and invasion. The migration assay was conducted using a cell culture insert with $8-\mu \mathrm{m}$ pore size (BD Biosciences, Bedford, MA, USA). Biocoat Matrigel (BD Biosciences) was used to evaluate cell invasion potential. Briefly, at $24 \mathrm{~h}$ after siRNA transfection, $1.0 \times 10^{5}$ cells per well were seeded in the upper chamber in serum-free medium. The lower chamber contained medium with $10 \%$ fetal bovine serum. The chambers were incubated at $37^{\circ} \mathrm{C}$ in $5 \% \mathrm{CO}_{2}$ for $48 \mathrm{~h}$ for the migration assay and invasion assay, and non-migrated or non-invaded cells were removed from the upper side of the membrane by scrubbing with cotton swabs. Migrated or invaded cells were then fixed on the membrane and stained with Diff-Quick staining reagents (Sysmex, Kobe, Japan). The migrated or invaded cells on the lower side of the membrane of each insert were counted in four independent fields of view at $\times 100$ magnification. Each assay was performed in triplicate.

Statistical analysis. Statistical analyses were carried out using Fisher's exact test to investigate the correlations between clinicopathological parameters and IP score. Survival curves were constructed using the Kaplan-Meier method, and differences in survival were examined using the log-rank test. Multivariate analysis of the factors influencing survival was performed using the Cox proportional hazards model. Student's $t$-test was used to evaluate continuous variables. Differences were considered significant when the associated $p$-value was less than 0.05. All analyses were performed using statistical software (JMP, version 10; SAS Institute Inc., Cary, NC, USA).

\section{Results}

TRPM7 protein expression in human ESCC. TRPM7 protein expression was not detected in non-cancerous esophageal epithelia (Figure 1A). TRPM7 protein was expressed in the cytoplasm of carcinoma cells (Figure 1B).

The IP score varied widely between the tumors. The minimum IP score was 0.1 , while the maximum was 2.1 (median=1.30; mean \pm standard deviation=1.36 \pm 0.40 ). Regarding the expression of TRPM7 in tumors, we divided patients with ESCC into two groups according to the mean IP score: a lowgrade TRPM7 expression group with IP score $<1.36(n=28)$, and a high-grade TRPM7 expression group with IP score $\geq 1.36$ $(n=24)$. Photographs of ESCC tumor samples with high and with low score are shown in Figure 1C. Relationships between the expression of TRPM7 and various clinicopathological parameters were analyzed according to TRPM7 expression group (Table I). The expression of TRPM7 was associated with pT and pN categories, pStage, and histological type (Table I).

Next, we analyzed the effect of TRPM7 expression on the survival of patients with ESCC. The 5-year survival rate of patients with high TRPM7 expression (82.6\%) was significantly higher than that of the patients with low expression (54.6\%) (Table II, Figure 2). We also assessed which of nine variables (age, gender, pT, pN categories, 
A

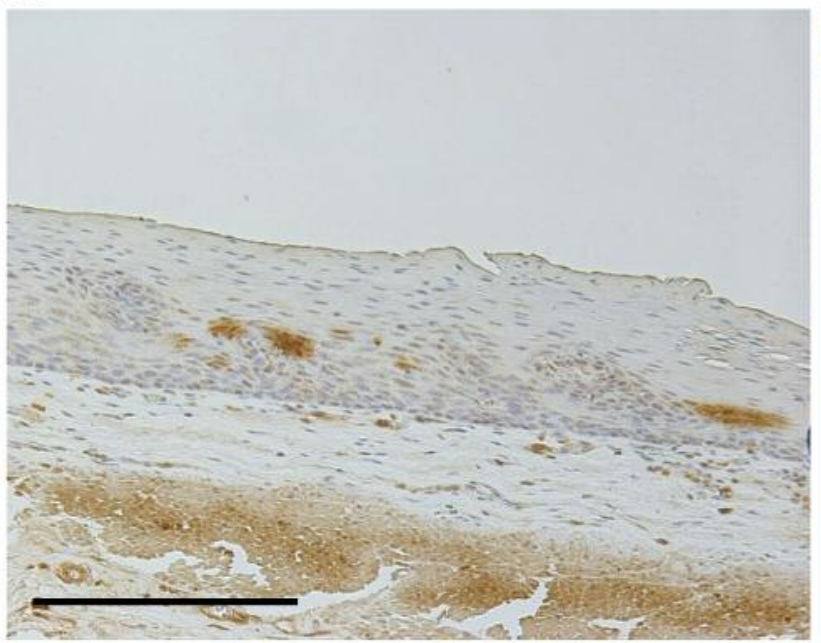

C

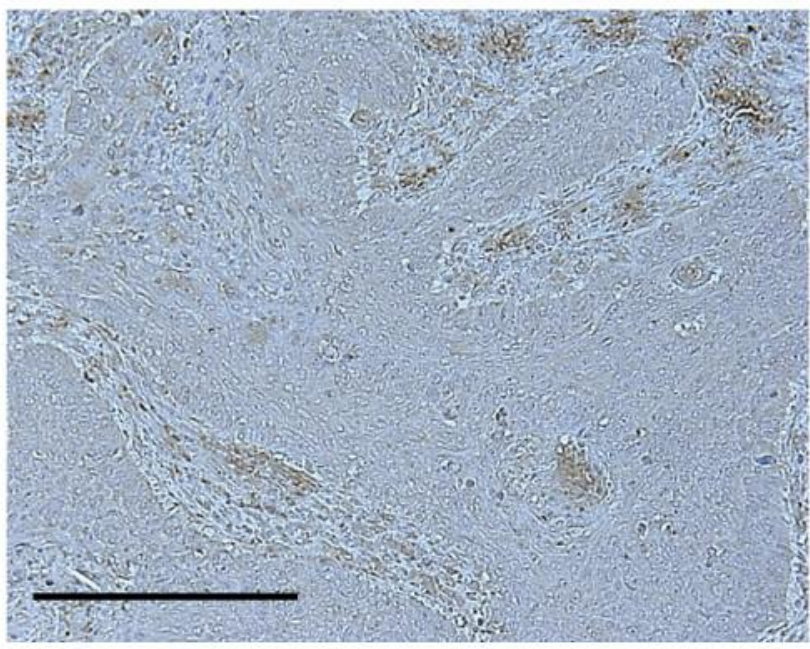

B

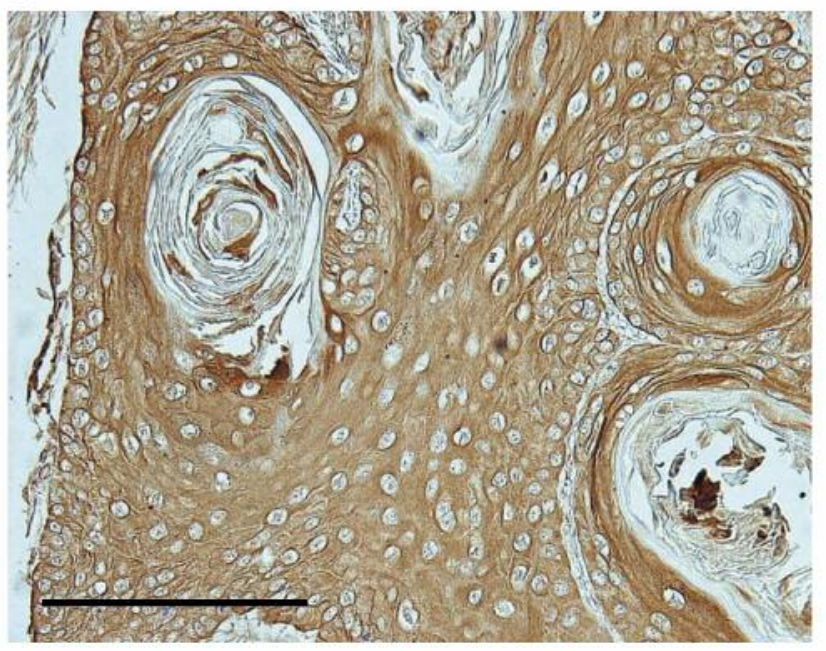

High IP score

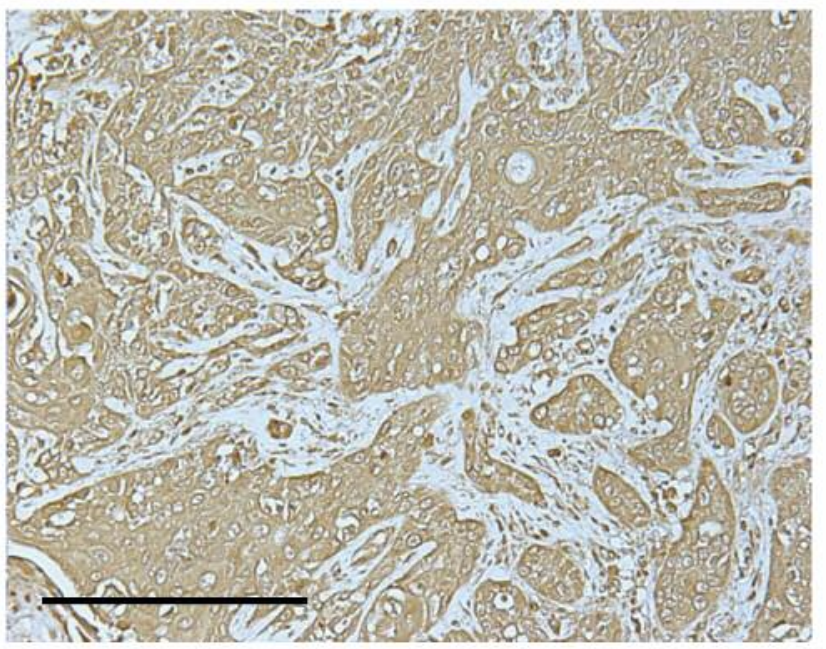

Figure 1. Immunohistochemical staining of non-cancerous esophageal epithelia (A) and primary human esophageal squamous cell carcinoma tumor samples $(B)$ with antibody against transient receptor potential malastatin 7 . Bar $=200 \mu \mathrm{m}$. C: Immunohistochemical staining of cases with high and low intensity proportion (IP) score. Bar $=200 \mu \mathrm{m}$.

pStage, histological type, lymphatic invasion, venous invasion, and IP score (cut-off value $=1.36$ ) influence survival after curative resection of ESCC. In univariate analysis of survival after esophagectomy, higher pT category, venous invasion, and low IP score were found to be factors associated with poorer prognosis $(p=0.022,0.026$, and 0.026 , respectively; Table II). Multivariate analysis demonstrated that IP score was an independent prognostic factor $(p=0.045)$ (Table III).

Expression of TRPM7 in ESCC cell lines. To determine the role of TRPM7 in ESCC, we examined six ESCC cell lines, TE2, TE5, TE9 TE13, KYSE70 and KYSE170, for mRNA expression of TRPM7. RT-PCR revealed that higher levels of TRPM7 expression were observed in the TE5 and KYSE70 cell lines (Figure 3A).

TRPM7 controls the cell proliferation, migration and invasion of ESCC cells. We conducted knockdown experiments with TRPM7 siRNA in TE5 TRPM7-overexpressing cells, and analyzed the effects of TRPM7 knockdown on cell proliferation, migration and invasion. TRPM7 siRNA effectively reduced the TRPM7 mRNA level (Figure 3B). The cell counts of TRPM7 siRNA-transfected cells were significantly higher than those of control siRNA-transfected 
Table I. Associations between the clinicopathological features of esophageal cancer and intensity proportion (IP) score.

\begin{tabular}{|c|c|c|c|c|}
\hline \multirow[t]{2}{*}{ Variable } & & \multicolumn{2}{|c|}{ IP score } & \multirow[t]{2}{*}{$p$-Value } \\
\hline & & $\begin{array}{c}\text { Low } \\
(\mathrm{n}=28)\end{array}$ & $\begin{array}{l}\text { High } \\
(\mathrm{n}=24)\end{array}$ & \\
\hline \multicolumn{5}{|l|}{ Age } \\
\hline & $<65$ Years & 15 & 16 & 0.336 \\
\hline & $\geq 60$ Years & 13 & 8 & \\
\hline \multirow[t]{2}{*}{ Gender } & Male & 23 & 20 & 0.910 \\
\hline & Female & 5 & 4 & \\
\hline \multirow[t]{2}{*}{ pT } & pT1 & 7 & 14 & $0.014^{*}$ \\
\hline & pT2-T3 & 21 & 10 & \\
\hline \multirow[t]{2}{*}{$\mathrm{pN}$} & pNO & 7 & 13 & $0.030 *$ \\
\hline & $\mathrm{pN} 1-3$ & 21 & 11 & \\
\hline \multirow[t]{2}{*}{ pStage } & I & 2 & 9 & $0.006^{*}$ \\
\hline & II-IV & 26 & 15 & \\
\hline \multirow[t]{2}{*}{ Histology } & Well-differentiated & 16 & 20 & $0.038 *$ \\
\hline & Poorly differentiated & 12 & 4 & \\
\hline \multirow[t]{2}{*}{ Lymphatic invasion } & Negative & 14 & 9 & 0.365 \\
\hline & Positive & 14 & 15 & \\
\hline \multirow[t]{2}{*}{ Venous invasion } & Negative & 13 & 15 & 0.245 \\
\hline & Positive & 15 & 9 & \\
\hline
\end{tabular}

$* p<0.05$ : Fisher's exact test.

Table II. The 5-year survival rate of patients with esophageal cancer according to various clinicopathological parameters.

\begin{tabular}{llcc}
\hline Variable & & $\begin{array}{c}\text { 5-Year survival } \\
\text { rate (\%) }\end{array}$ & $p$-Value \\
\hline Age & 665 Years & 66.3 & 0.916 \\
& $\geq 65$ Years & 70.0 & \\
Gender & Male & 66.1 & 0.544 \\
& Female & 76.2 & \\
pT & pT1 & 85.2 & $0.022^{*}$ \\
pN & pT2-3 & 56.4 & \\
& pN0 & 79.7 & 0.164 \\
pStage & pN1-3 & 60.4 & \\
& I & 90.9 & 0.085 \\
Histology & II-IV & 61.7 & \\
\multirow{2}{*}{ Lymphatic invasion } & Well-differentiated & 70.9 & 0.501 \\
& Poorly differentiated & 60.9 & \\
Venous invasion & Negative & 67.5 & 0.173 \\
& Positive & 57.7 & \\
IP score & Negative & 81.0 & $0.026^{*}$ \\
& Positive & 52.9 & \\
& Low & 54.6 & $0.026^{*}$ \\
& High & 82.6 & \\
\hline
\end{tabular}

IP: Intensity proportion. ${ }^{*} p<0.05$ : Log-rank test.

cells $48 \mathrm{~h}$ after siRNA transfection (Figure 3C). Furthermore, down-regulation of TRPM7 significantly increased cell migration and invasion (Figure 3D). These results suggest that TRPM7 plays an important role in the regulation of cell proliferation, migration and invasion in TE5 cells.

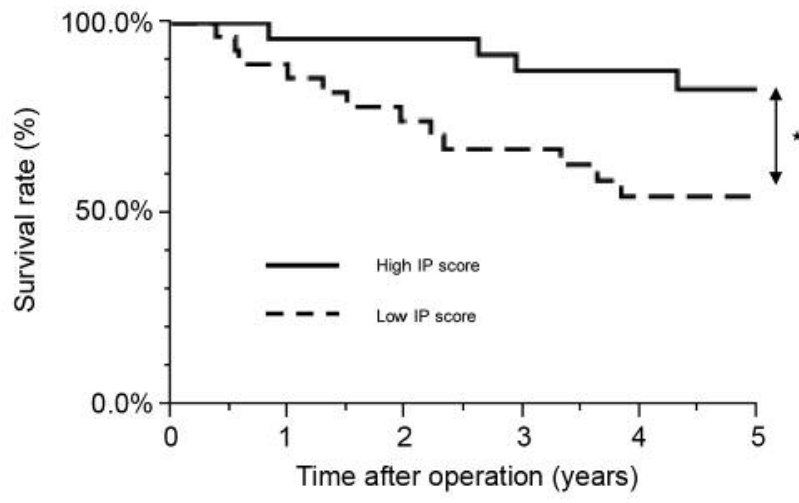

Figure 2. Survival curve of patients with esophageal cancer using the Kaplan-Meier method. The patients were classified into two groups according intensity proportion (IP) score; a low-grade transient receptor potential malastatin 7 (TRPM7) expression group with IP score $<1.36(n=28)$, and a high-grade TRPM7 expression group with IP score $\geq 1.36(n=24)$. Statistical analysis: log-rank test $(* p<0.05)$.

Table III. Prognostic factors of esophageal cancer according to multivariate analysis.

\begin{tabular}{|c|c|c|c|c|}
\hline Variable & & Risk ratio & $95 \% \mathrm{CI}$ & $p$-Value \\
\hline \multirow{2}{*}{ pT } & pT1 & 1 & & \\
\hline & pT2-3 & 3.136 & $0.976-13.98$ & 0.055 \\
\hline \multirow[t]{2}{*}{ Venous invasion } & Negative & 1 & & \\
\hline & Positive & 2.505 & $0.904-8.000$ & 0.078 \\
\hline \multirow[t]{2}{*}{ IP score } & Low & 1 & & \\
\hline & High & 0.334 & $0.091-0.995$ & $0.045^{*}$ \\
\hline
\end{tabular}

IP: Intensity proportion; CI: confidence interval; $* p<0.05$ : Cox's proportional hazards model.

\section{Discussion}

Radical esophagectomy is the primary curative therapy for patients with ESCC, and recent advances in surgical techniques and perioperative management strategies have improved the surgical outcome of $\operatorname{ESCC}(19,20)$. However, patients with advanced disease still frequently develop recurrence, and the prognosis of these patients remains poor (21-23). To predict the treatment outcomes of patients with ESCC, it is important to understand the proliferative activity of ESCC tumor cells and its prognostic impact.

TRPM7 is both an ion channel and a protein kinase that regulates various cellular processes in many solid tumor types. However, it has not been evaluated in ESCC. To our knowledge, this is the first report examining TRPM7 and ESCC.

There have been other reports about the clinicopathological role of TRPM7 in several type of cancer (24-26) but their 

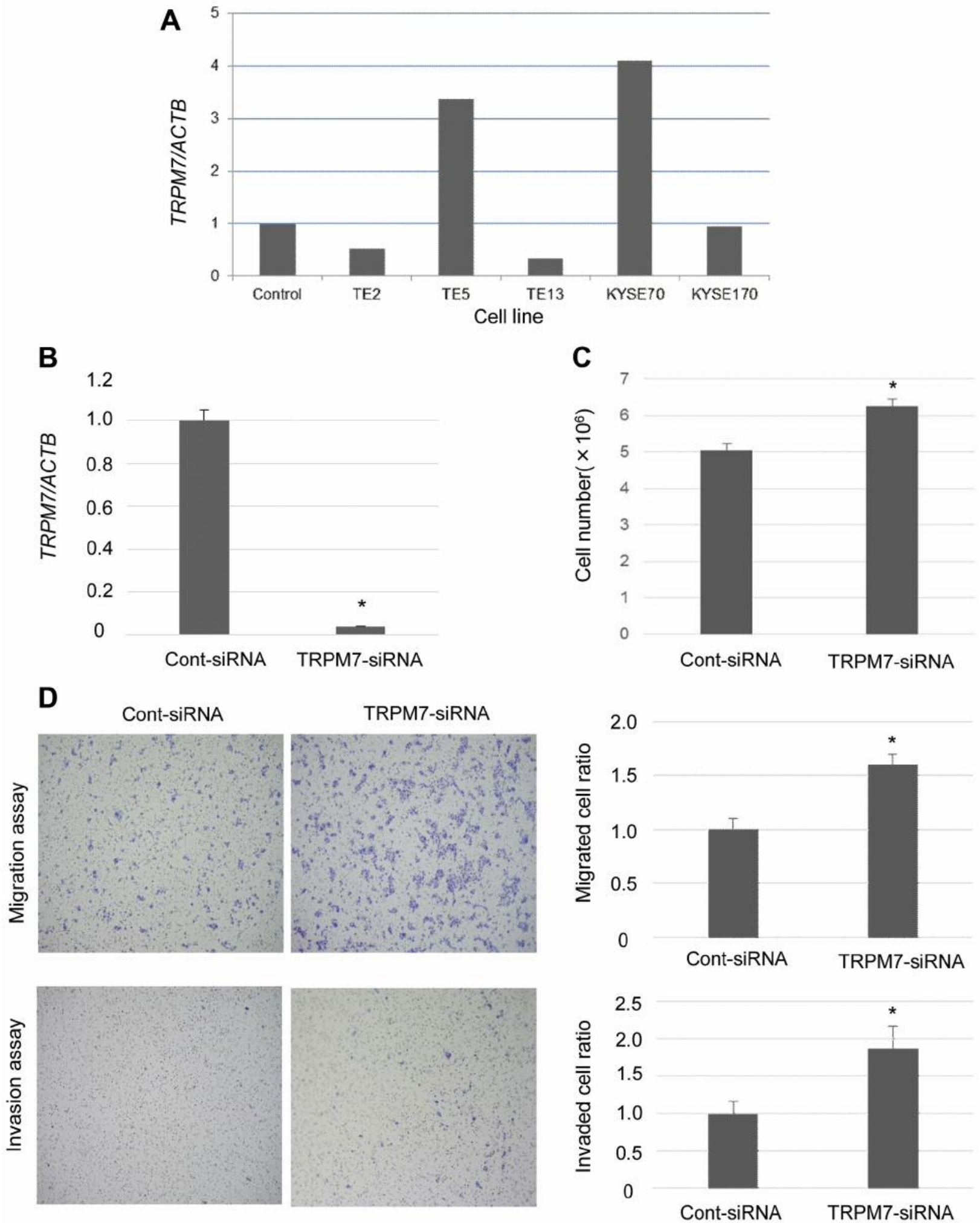

Figure 3. A: Transient receptor potential malastatin 7 (TRPM7) mRNA level was analyzed in six esophageal squamous cell carcinoma cell lines. B: TRPM7 siRNA effectively reduced the mRNA level of TRPM7 in TE5 cells. C: TRPM7 down-regulation significantly increased the proliferation of TE5 cells. D: TRPM7 down-regulation significantly increased cell migration and invasion by TE5 cells. Data are the mean $\pm S E M$. $n=3$. * $p<0.05$ Compared with the control siRNA group. 
results were inconclusive. In our study, TRPM7 expression was correlated with pT, pN categories, pStage, and histological type. Dhennin-Duthille et al. found that TRPM7 was overexpressed mainly in human breast ductal adenocarcinoma presenting high tumor grade associated with a large tumor size (>2 cm) (24). Yee et al. demonstrated a statistically significant positive association of primary tumor size and tumor stage with the anti-TRPM7 immunohistochemistry score in pancreatic adenocarcinoma (25). Wang et al. showed that TRPM7 protein was associated pelvic metastasis (26). Contrary to these reports, our results suggest that TRPM7 is negative correlated with pT and $\mathrm{pN}$ category and pStage in ESCC.

We showed that the 5-year survival rate of the patients with high TRPM7 expression was significantly higher than that of those with low expression, in addition TRPM7 expression was an independent factor predicting good prognosis for patients with ESCC. Rybarczyk et al. demonstrated that TRPM7 was a potential biomarker of poor prognosis of pancreatic ductal adenocarcinoma (14). Wang et al. showed that overexpression of TRPM7 was significantly associated with poor prognosis in patients with ovarian cancer (26). Middelbeek et al. reported that TRPM7 was a strong and independent poor prognostic marker for breast cancer progression and metastasis (27). Our results were contrary to these previous reports for other carcinoma types.

Furthermore, we found that down-regulation of TRPM7 significantly increased cell proliferation, migration and invasion. There were various results in other reports, the results were controversial. Leng et al. reported that suppression of TRPM7 expression with TRPM7-siRNA dramatically reduced the proliferation, migration and invasion of glioma cells (8). Rybarczyk et al. demonstrated that the down-regulation of TRPM7 by siRNA dramatically inhibited cell migration without affecting cell proliferation in pancreatic ductal adenocarcinoma cells (14). Meng et al. showed that silencing TRPM7 with RNA interference significantly reduced the migration and invasion capability of breast cancer cells (28).

Mizuno et al. reported that TRPM7-overexpressing mouse bladder cancer cells proliferated more slowly compared to mock-transfected cells. TRPM7 negatively regulated bladder cancer cell proliferation similar to our findings (10). Unlike most previous reports for other types of carcinomas, they found that TRPM7 exhibited the ability to inhibit tumor progression in ESCC.

The expression levels of members of the TRP family are correlated with the progression of various cancer types (29). However, the physiological roles of these TRP channels vary according to cancer type. TRPV2 expression level and TRPV2 activator-induced intracellular $\mathrm{Ca}^{2+}$ increase were significantly higher in mouse bladder cancer cells compared to normal mouse urothelial cells. The proliferation rate of mouse bladder cancer cells overexpressing dominant-negative TRPV2 was significantly increased. In contrast, treatment with TRPV2 activators significantly reduced the proliferation rate. TRPV2 served as negative regulators of bladder cancer cell proliferation (10). As for TRPM8, TRPM8 activation suppressed the viability of human melanoma cells (30). A growing number of studies have demonstrated that increases in $\mathrm{Ca}^{2+}$ regulate various signaling mechanisms that control a variety of cellular processes such as proliferation, metabolism, and gene transcription; yet under certain conditions, increases in $\mathrm{Ca}^{2+}$ are cytotoxic (31). The determination of molecular mechanisms involved in TRPM7-mediated ESCC cell proliferation, migration and invasion are yet to be understood. Further studies are required to elucidate the function of TRPM7 in ESCC.

In conclusion, TRPM7 is negatively correlated with pT and $\mathrm{pN}$ category and pStage, and can be used as an independent good prognostic factor for patients with ESCC.

\section{Acknowledgements}

This work was supported by a Grant-in-Aid for Scientific Research (C) (26461988) from the Japan Society for the Promotion of Science.

\section{References}

1 Nilius B and Owsianik G: The transient receptor potential family of ion channels. Genome Biol 12: 218, 2011.

2 Paravicini TM, Chaubanov V and Gudermann T: TRPM7: a unique channel involved in magnesium homeostasis. Biochem Cell Biol 44: 1381-1384, 2012.

3 Wykes RC, Lee M, Duffy SM, Yang W, Seward EP and Bradding P: Functional transient receptor potential melastatin 7 channels are critical for human mast cell survival. J Immunol 179: 4045-4052, 2007.

4 Kim BJ, Park EJ, Lee JH, Jeon JH, Kim SJ and So I: Suppression of transient receptor potential melastatin 7 channel induces cell death in gastric cancer. Cancer Sci 99: 2502-2509, 2008.

5 Abed E and Moreau R: Importance of melastatin-like transient receptor potential 7 and cations (magnesium, calcium) in human osteoblast-like cell proliferation. Cell Prolif 40: 849-865, 2007.

6 Hanano T, Hara Y, Shi J, Morita H, Umebayashi C, Mori E, Sumimoto H, Ito Y, Mori Y and Inoue R: Involvement of TRPM7 in cell growth as a spontaneously activated $\mathrm{Ca}^{2+}$ entry pathway in human retinoblastoma cells. J Pharmacol Sci 95: 403-419, 2004.

7 Jiang J, Li MH, Inoue K, Chu XP, Seeds $\mathrm{J}$ and Xiong ZG: Transient receptor potential melastatin 7-like current in human head and neck carcinoma cells :role in cell proliferation. Cancer Res 67(22): 10929-10938, 2007.

8 Leng TD, Li MH, Shen JF, Liu ML, Li XB, Sun HW, Branigan D, Zeng Z, Si HF, Li J, Chen J and Xiong ZG: Suppression of TRPM7 inhibits proliferation, migration and invasion of malignant human glioma cells. CNS Neurosci Ther 21: 252-261, 2015.

9 Sun Y, Sukumaran P, Varma A, Derry S, Sahmoun AE and Singh BB: Cholesterol-induced activation of TRPM7 regulates cell proliferation, migration, and viability of human prostate cells. Biochim Biophys Acta 1843: 1839-1850, 2014. 
10 Mizuno H, Suzuki Y, Watanabe M, Sokabe T, Yamamoto T, Hattori R, Gotoh M and Tominaga M: Potential role of transient receptor potential (TRP) channels in bladder cancer cells. J Physiol Sci 64: 305-314, 2014.

11 Prevarskaya N, Skryma R and Shuba Y: Calcium in tumour metastasis:new roles for known actors. Nat Rev Cancer 11: 609618, 2011.

12 Chen JP, Luan Y, You CX, Chen XH, Luo RC and Li R: TRPM7 regulates the migration of human nasopharyngeal carcinoma cell by mediating $\mathrm{Ca}(2+)$ influx. Cell Calcium 47: 425-432, 2010.

13 Guilbert A, Gautier M, Dhennin-Duthille I, Rybarczyk P, Sahni J, Sevestre H, Scharenberg AM and Ouadid-Ahidouch H: Transient receptor potential melastatin 7 is involved in oestrogen receptor-negative metastatic breast cancer cells migration through its kinase domain. Eur J Cancer 49: 3694-3707, 2013.

14 Rybarczyk P, Gautier M, Hague F, Dhennin-Duthille I, Chatelain D, Kerr-Conte J, Pattou F, Regimbeau JM, Sevestre H and Ouadid-Ahidouch H: Transient receptor potential melastatinrelated 7 channel is overexpressed in human pancreatic ductal adenocarcinomas and regulates human pancreatic cancer cell migration. Int J Cancer 131: E851-861, 2012.

15 Sobin L, Gospodarowicz $M$ and Wittekind C: TNM Classification of malignant tumors. Seventh Edition. Hoboken, NJ: John Wiley \& Sons, Inc, 2009.

16 Remmele W and Stegner HE: Recommendation for uniform definition of an immunoreactive score (IRS) for immunohistochemical estrogen receptor detection (ER-ICA) in breast cancer tissue. Pathology 8: 138-140, 1987.

17 Nishihira T, Hashimoto Y, Katayama M, Mori S and Kuroki T: Molecular and cellular features of esophageal cancer cells. J Cancer Res Clin Oncol 19: 441-449, 1993.

18 Shimada Y, Imamura M, Wagata T, Yamaguchi $\mathrm{N}$ and Tobe T: Characterization of 21 newly established esophageal cancer cell lines. Cancer 69: 277-284, 1992.

19 Ozawa S, Tachimori Y, Baba H, Fujishiro M, Matsubara H, Numasaki H, Oyama T, Shinoda M, Takeuchi H, Teshima T, Udagawa H, Uno T and Barron JP: Comprehensive Registry of Esophageal Cancer in Japan. Esophagus 9: 75-98, 2012.

20 Ando N, Ozawa S, Kitagawa Y, Shinozawa Y and Kitajima M: Improvement in the results of surgical treatment of advanced squamous esophageal carcinoma during 15 consecutive years. Ann Surg 232: 225-232, 2000.

21 Nakagawa S, Kanda T, Kosugi S, Ohashi M, Suzuki T and Hatakeyama K: Recurrence pattern of squamous cell carcinoma of the thoracic esophagus after extended radical esophagectomy with three-field lymphadenectomy. J Am Coll Surg 198: 205211,2004
22 Shimada H, Kitabayashi H, Nabeya Y, Okazumi S, Matsubara H, Funami Y, Miyazawa Y, Shiratori T, Uno T, Itoh H and Ochiai $\mathrm{T}$ : Treatment response and prognosis of patients after recurrence of esophageal cancer. Surgery 133: 24-31, 2003.

23 Kunisaki C, Makino H, Takagawa R, Yamamoto N, Nagano Y, Fujii S, Kosaka T, Ono HA, Otsuka Y, Akiyama H, Ichikawa Y and Shimada H: Surgical outcomes in esophageal cancer patients with tumor recurrence after curative esophagectomy. J Gastrointest Surg 12: 802-810, 2008.

24 Dhennin-Duthille I, Gautier M, Faouzi M, Guibert A, Brevet M, Vaudry D, Ahidouch A, Sevestre H and Ouadid-Ahidouch H: High expression of transient receptor potential channels in human breast cancer epithelial cells and tissues: correlation with pathological parameters. Cell Physiol Biochem 28: 813-822, 2011.

25 Yee NS, Kazi AA, Li Q, Yang Z, Berg A and Yee RK: Aberrant over-expression of TRPM7 ion channels in pancreatic cancer: required for cancer cell invasion and implicated in tumor growth and metastasis. Biology Open 4: 507-514, 2015.

26 Wang J, Xiao L, Luo CH, Zhou H, Hu J, Tang YX, Fang KN and Zhang Y: Overexpression of TRPM7 is associated with poor prognosis in human ovarian carcinoma. Asian Pac J Cancer Prev 15: 3955-3958, 2014.

27 Middelbeek J, Kuipers AJ, Henneman L, Visser D, Eidhof I, van Horssen R, Wieringa B, Canisus SV, Zwart W, Wessels LF, Sweep FC, Bult P, Span PN, van Leeuwen FN and Jalink K: TRPM7 is required for breast tumor cell metastasis. Cancer Res 72: 4250-4261, 2012.

28 Meng X, Cai C, Wu J, Cai S, Ye C, Chen H, Yang Z, Zeng H, Shen $Q$ and Zou F: TRPM7 mediates breast cancer cell migration and invasion through the MAPK pathway. Cancer Lett 333: 96-102, 2013.

29 Prevarskaya N, Zhang L and Barritt G: TRP channels in cancer. Biochim Biophys Acta 1772: 937-946, 2007.

30 Yamamura H, Ugawa S, Ueda T, Morita A and Shimada S: TRPM8 activation suppresses cellular viability in human melanoma. Am J Physiol Cell Physiol 295: C296-C301, 2008.

31 Roderick HL and Cook SJ: $\mathrm{Ca}^{2-}$ Signaling checkpoints in cancer: remodelling $\mathrm{Ca}^{2+}$ for cancer cell proliferation and survival. Nat Rev Cancer 8: 361-375, 2008.
Received January 4, 2017

Revised February 14, 2017

Accepted February 21, 2017 